\title{
Desempleo, organización y política. Los trabajadores rurales del sur chileno frente a la Gran Depresión
}

\author{
Ernesto Bohoslavsky \\ Instituto Universitario Ortega y Gasset, Madrid
}

En este artículo se da cuenta de algunas de las reacciones de los trabajadores rurales de la región chilena de la Araucanía frente al desempleo generado a partir de la Gran Depresión. Se intenta superar la noción común que sostiene el carácter sumiso de los inquilinos, señalando las organizaciones sindicales conformadas en la década de los '30, así como las respuestas no institucionales e ilegales (cuatrerismo, pequeños hurtos, saqueos). También se mencionan las influencias provenientes del mundo urbano y la importancia del horizonte nacional en la constitución de esos sindicatos.

Palabras ClaVe: Chile, Trabajadores rurales, Siglo XX, Araucanía, Desempleo.

This article discusses some of the reactions of the rural land-less workers (peones) and tenants (inquilinos) to the unemployment in the Chilean Araucania Region, during the Great Depression. Furthermore, the paper wants to review the conceptions about the supposed passivity of the tenants, showing the rural workers' associations created around the '1930s, as much as the non-institutional and illegal responses (cattle-lifting, petty robbery, popular sacking). Here are mentioned too the urban influences detected in this process, as much as the importance of the national political realm in the building of these rural workers associations.

KEYwords: Chile, Rural Workers, 20 th Century, Araucanía, Unemployment.

La región de la Araucanía, en el centro-sur chileno, comprendida entre los ríos Bío Bío y Toltén, tiene ganada a lo largo de la historia una justa fama. La expansión de las fuerzas incaicas encontró en ella su insuperable límite sudoccidental. No tuvo mejor suerte la temprana intentona de los conquistadores, que comprendieron que la paz era más rentable que la guerra con los mapuches. Durante los tiempos de la Colonia, y en las primeras décadas republicanas, las sociedades indígenas fueron capaces de mantener a raya los intentos de las sucesivas administraciones por someterlos e incorporar sus tierras a la economía nacional y mundial.

La historia cambió definitivamente a fines del siglo XIX, cuando la simultánea operación de los ejércitos argentino (1879) y chileno (1881) eliminó el último reducto físico de soberanía que les faltaba a ambos estados. 
Las fértiles tierras de la Araucanía, fueron muy rápidamente reconvertidas a la producción agrícola, básicamente triguera. En pocos años esa región se convirtió en la principal productora de cereales del país, asumiendo sus dos provincias, Cautín y Malleco, un rol considerable en la economía nacional. Este proceso de reconfiguración del paisaje agrario y de organización de una sociedad que pretendía dejar de ser "frontera", ha sido bastante estudiado por los historiadores chilenos. ${ }^{1}$ El barrido historiográfico de la Araucanía ha sido notorio tanto para ese período como para el colonial. Pero los estudios sobre el mundo agrario, los trabajadores y las organizaciones sindicales de esta región en el siglo XX son, todavía, áreas poco rastrilladas por la historiografía chilena. Juan Quintar ha llegado a la misma conclusión al realizar un estado de la cuestión de los estudios históricos sobre la Araucanía:

los investigadores chilenos han afirmado que en estos espacios no ha existido lo que está aceptado para el conjunto de los trabajadores en la historiografía chilena, el movimiento mutualista y las mancomunales. Más aun, se nos informa que ni siquiera las organizaciones gremiales tienen presencia allí. ${ }^{2}$

Se ha sostenido que el aislamiento político al que estaban sometidos los trabajadores rurales y el férreo despliegue de la autoridad latifundista, por lo general, desarticulaban las organizaciones sindicales y las resistencias frente a los avasallamientos sobre derechos y propiedades de los trabajadores rurales. ${ }^{3}$ En efecto, la interpretación más difundida sostiene que recién en la segunda mitad del siglo XX se pueden descubrir movimientos intensivos de fuerzas sociales en el campo, que incluyeron las diversas iniciativas de Reforma Agraria.

1 Especialmente relevantes son los trabajos de José Bengoa, Guillermo Bravo Acevedo, Holdenis Casanova, Carmen Norambuena Carrasco, Jorge Pinto Rodríguez y, especialmente, de Sergio Villalobos. Por otro lado, las décadas cercanas a la actualidad, han sido analizadas más sistemáticamente por la sociología rural, especialmente por los integrantes del Grupo de Investigaciones Agrarias de la Academia de Humanismo Cristiano. Algunas de esas obras serán oportunamente mencionadas.

2 Quintar, Juan: Informe de avance del proyecto "Vida material, sociabilidad y cultura de los sectores populares en el sur de Chile y Argentina, 1885-1950”, Universidad Nacional del Comahue, Neuquén, 1997, pag. 10. Uno de los pocos trabajos que da cuenta de una experiencia sindical es el ofrecido por Palacios Ríos, Germán: Ranquil. La violencia en la expansión de la propiedad agrícola, ICAL, Santiago de Chile, 1992.

3 Como prueba de la tardanza de la sindicalización rural en afianzarse se señala que en 1961 en todo Chile existían sólo 22 sindicatos rurales, con menos de 2000 miembros. Vio Grossi, Francisco: Resistencia campesina en Chile y México, C.E.A.A.L., Santiago de Chile, 1990. 
Este vacío historiográfico en torno a la primera mitad del siglo XX es el que nos ha llevado a profundizar las investigaciones en torno a los principales grupos de trabajadores rurales organizados de la Araucanía, con la convicción de que es posible ofrecer un panorama más complejo de lo que se ha mostrado hasta ahora. El objetivo a desarrollar en este escrito es, pues, dar cuenta de algunas de las asociaciones que conformaron los trabajadores rurales de Malleco y Cautín, principalmente los sindicatos de colonos y aspirantes a la tierra, en el contexto de la primera gran crisis del capitalismo en el siglo XX, atendiendo especialmente a las relaciones entre los efectos económicos de 1929 y la organización de los trabajadores rurales. ${ }^{4}$

La crisis económica colaboró para que la sindicalización rural continuara siendo prácticamente una misión imposible por la oposición de la organización patronal (Sociedad Nacional de Agricultura) y por el endurecimiento de la represión de los gobiernos de Ibáñez (1927-1931) y de Arturo Alessandri (1932-1936). Pese a ello, algunos niveles de agitación social se expresaron en el campo. Allí, la demanda no sólo se orientó a mejorar las condiciones de vida y de trabajo sino a la aplicación del Código de Trabajo de 1931, lo que implicaba, como señaló Bengoa, la urticante cuestión de reconocer legalmente a los sindicatos campesinos. ${ }^{5} \mathrm{Si}$ se quiere, el problema de la sindicalización rural no encontró una canalización efectiva sino hasta los años del primer Frei en la década de 1960. Hasta entonces, la política habitual era la represión abierta o la siembra de todo tipo de obstáculos a la efectiva organización sindical rural, con el resultado de que se atomizaban las voluntades campesinas y los partidos de derecha mantenían su caudal electoral. Ni siquiera los gobiernos del Frente Popular pudieron $-\mathrm{o}$ quisieron, o se atrevieron a- modificar demasiado la política con respecto a la sindicalización agraria.

Claro está que la debilidad de los movimientos campesinos no era privativa de Chile sino que podía ser rastreada en casi toda América Latina. Pero sí es significativo señalar la gran diferencia existente entre esa dificultad para lograr la organización sindical en áreas rurales con la fuerte organización gremial chilena, basada en la minería del norte chileno y los

4 Hemos dejado de lado explícitamente a trabajadores de origen mapuche que seguían viviendo en el régimen de reducciones, por entender que se trata de un universo con fuertes particularidades culturales y sociales. Para el tema son inevitables las obras de Bengoa, José: Historia del pueblo mapuche, Sur, Santiago de Chile, 1989, e Historia de un conflicto. El estado y los mapuches en el siglo XX, Ariel-Planeta, Santiago de Chile, 1999.

5 Bengoa, José: Historia del movimiento campesino, G.I.A., Santiago de Chile, 1983. 
trabajadores agrupados en zonas urbanas. Pero aunque esta diferencia entre el mundo rural y otras áreas existía, pensamos que no debe seguir considerándose a los campesinos y trabajadores rurales como sujetos dóciles. Entendemos que es posible hallar casos de sindicalismo rural en la Araucanía durante la década de 1930, aunque se trató de experiencias breves y, en muchos casos, de escaso impacto.

En general, la bibliografía histórica ha tratado a los campesinos, especialmente a los inquilinos, como incapaces de otra cosa que resignación y obediencia ciega al patrón, reproducida por el carácter hereditario del inquilinaje y por la naturaleza cíclica del trabajo agrícola. Se ha insistido demasiado en la supuesta pasividad intrínseca del inquilino y su integración funcional a la sociedad rural chilena. ${ }^{6}$ En esos estudios sobre el inquilinaje se esconde una noción centrada en la pasividad y la sumisión permanentes del campesinado a la dominación estatal y hacendal, desdeñando su capacidad de resistencia.

Por el contrario, consideramos que esta visión es, si no equivocada, al menos exagerada. Intentaremos mostrar que los inquilinos en la Araucanía fueron capaces de organizarse para exigir el cumplimiento de derechos, resistir desalojos y ocupar tierras. Quizás sólo sea cuestión de entender que las reacciones que esgrimían eran más lentas que los que podían desarrollar otros grupos, dado que tenían que atender a un número mayor de problemas, como el hecho de tener familia o depender de la voluntad patronal para seguir cultivando la tierra. Si se permite la metáfora, los inquilinos tenían una mecha más larga, pero no por eso dejaban de tener carga explosiva. Sentencias tales como "domesticados generación tras generación por patrones, curas y capataces, los inquilinos parecen no tener escapatoria a un destino que los amarra a la tierra y a un patrón", ${ }^{7}$ esperamos que puedan ser, al menos, discutidas.

En cuanto a los trabajadores temporales de los fundos, es decir, los peones afuerinos y los gañanes, podemos sostener que no ofrecían instancias estables de asociación y organización sindical: su vida y desarrollo laboral se encontraban centrados en un fuerte individualismo y en una permanente rotación laboral y domiciliaria. Sin embargo, es posible encontrar

6 Atropos: "El inquilino en Chile. Su vida. Un siglo sin variaciones, 1861-1966", Revista Mapocho, tomo V, núm. 2-3, Biblioteca Nacional, Santiago de Chile, 1966 y Bengoa, José: Historia social de la agricultura chilena, Sur, Santiago de Chile, tomo II, 1988.

7 Valdés, Ximena y otras: Masculino y femenino en la hacienda chilena del siglo XX, C.E.D.E.M., Santiago, 1995, pag. 64. 
entre ellos algunos ejercicios individuales y grupales de resistencia de escaso alcance, por lo general "ilegales", especialmente estimulados por el desempleo y, en algunos casos, el hambre. Estas actividades eran realizadas las más de las veces por los desocupados en los ámbitos urbanos de la región en que conseguían alojamiento y alimentación.

\section{Trabajadores, desempleo y crisis de 1930 en la Araucanía}

Un informe producido por la Sociedad de las Naciones en 1932 indicaba que Chile era el país más afectado en el mundo por la Depresión desatada dos años atrás. ${ }^{8}$ La caída en los precios de los productos primarios afectó gravemente a las exportaciones nacionales. Ése no era el único problema, también influyeron los avances de la química alemana, que terminaron prácticamente por desplazar al salitre. Aunque la crisis salitrera se venía arrastrando desde mediados de la década de 1920, estos años no hicieron sino profundizar el conflicto, arrojando a varios miles de mineros desempleados a los centros urbanos del país. En 1931 se agravó aun más la situación ya que cerraron más empresas dedicadas al cobre, al salitre y al carbón. El incremento del paro fue notorio en la minería norteña, tradicional imán para los trabajadores: entre 1929 y 1931 la producción salitrera cayó prácticamente a la mitad y el número de trabajadores del cobre y el salitre bajó de 104.000 a 42.000 en igual período. ${ }^{9}$

Similar suerte corrieron muchos peones temporales y otros miles de trabajadores poco calificados que desarrollaban sus tareas en el agro. En 1930 el paro agrario alcanzó el 18,3\%, frente a una tasa global de 9,9\%. La Araucanía, región eminentemente agrícola, acusó recibo del galopante desempleo. ${ }^{10}$ Por su configuración minifundista de la tierra, Cautín era una de las provincias en las que había una proporción mayor de pequeñas propiedades agrarias familiares. La acentuada presencia de explotaciones fami-

8 Citado en Palma, Gabriel: Chile 1914-1935: de economía exportadora a sustitutiva de importaciones, CIEPLAN-Alfabeta, Santiago de Chile, 1984.

9 Collier, Simon y Sater, William: Historia de Chile, 1808-1994, Cambridge University Press, Madrid, 1998, págs. 197-98. Gallegos, Corina y Lara, Rodrigo: La crisis de 1929 y sus efectos en el desarrollo regional. El caso de Temuco: 1929-1933, UFRO, Temuco, 1986, pág. 13.

10 El diario Nuevos Tiempos, de Temuco, 6 de julio de 1932, pág. 2, sostenía que "el asunto de mayor importancia por resolver en nuestra provincia es el grave problema creado por la pavorosa cesantía que invade los campos y ciudades de nuestra provincia". Archivo de la Biblioteca Nacional, de ahora en adelante $\mathrm{ABN}$, Santiago de Chile. 
liares generó una rigidez del mercado de trabajo rural que dificultaba la potencial absorción de los parados, según Guillermo Bravo Acevedo. ${ }^{11}$

Los precios agrícolas se redujeron un 27\% entre 1927 y 1934: esta tendencia decreciente se mantuvo por 15 años más, convirtiéndose, al parecer, en una de las causas del estancamiento estructural del sector. ${ }^{12}$ La producción agroganadera se enfrentó a una demanda interna de alimentos contraída como efecto del desempleo. A esta situación se le sumaba el agotamiento de la frontera agrícola y la baja productividad agraria. Buena parte de los costos de esta caída relativa de la rentabilidad agraria fue remitida a los trabajadores rurales, que vieron deteriorados niveles de ingreso y sus niveles de vida durante la década de 1930. Por entonces sus condiciones habitacionales, educativas, sanitarias y de consumo eran ya de marcada pobreza, más allá de las disimilitudes en las categorías laborales o en las identidades étnicas.

Por entonces, la precariedad era la regla, confluyendo todas las variables en un acortamiento de la esperanza de vida: dietas pobres, pésimas condiciones habitacionales, bajos salarios, tierras escasas, un pobre sistema sanitario y un contexto inflacionario conspiraban contra la calidad de vida de las familias de peones e inquilinos. A esa situación se sumaba una escasa capacidad de presión política de los trabajadores rurales y de las comunidades mapuches sobre el Estado y las clases dirigentes, dificultando la llegada de la asistencia social y la cobertura legal, tornando escasamente fructíferas sus pujas por redistribución de recursos estatales.

Aunque no fuera en el sentido deseado por muchos campesinos, el Estado comenzó a actuar. Desde 1932 se fueron desarrollando instituciones y mecanismos estatales con dos propósitos: reducir todo lo que se pudiera la precariedad material y organizar y regular un mercado de trabajo seriamente afectado, incluso en pequeños ámbitos urbanos y rurales. Teniendo en cuenta que el informe de la Sociedad de las Naciones de 1932 indicaba que un $75 \%$ de los chilenos se alimentaba de manera deficiente o tenía pro-

11 "La potencialidad productiva recaía en las provincias de mayor concentración de la propiedad que, lógicamente, ofrecían y ocupaban un mayor porcentaje de fuerza de trabajo asalariada, pero que también estaban expuestas a sufrir con mayor rigor los efectos de la crisis". Bravo Acevedo, Guillermo: "El mercado de trabajo y la crisis de 1929. Una aproximación a la problemática de 1930", Cuadernos de Historia, núm. 10, Universidad de Chile, Santiago de Chile, 1990, pág. 135.

12 Huerta, Antonieta: Otro agro para Chile. La historia de la Reforma Agraria en el proceso social y político, CISEC-CESOC, Santiago de Chile, 1989. Para una postura contraria en el tema precios, Bauer, Arnold: La sociedad rural chilena. Desde la conquista española a nuestros días, Andrés Bello, Santiago, 1994. 
blemas de desnutrición, uno de los esfuerzos fue conducido hacia el control de precios de los bienes de primera necesidad. Se implementaron mecanismos de entrega de alimentos y se amplió la oferta de alojamiento gratuito en diversos edificios. Sin embargo, las estrategias del gobierno nacional poco pudieron hacer para contrarrestar la dramática situación social. El empleo público no aparecía como una posibilidad cierta: sólo a fines de la década de 1930 y sobre todo después de los años cuarenta, las grandes agencias de desarrollo (como la Corporación de Fomento, CorFo) y las iniciativas estatales ayudaron a combatir la desocupación.

Otra de las respuestas ensayadas por el Estado frente a la crisis laboral fue el traslado de trabajadores a provincias que ofrecieran mejores posibilidades, tal como parecía ser el caso de la Araucanía. ${ }^{13}$ En 1934 recorrían la región algunos agentes estatales dedicados a la leva de parados, para emplearlos en lavaderos auríferos privados. ${ }^{14}$ Esta decisión permitió reducir en parte el desempleo en la región, pero de ninguna manera lo extirpó. ${ }^{15}$ Por el contrario, el paro se dejaba ver especialmente después de las cosechas. Terminadas esas faenas, miles de trabajadores con las familias a cuestas iban a la ciudad de Temuco en busca de un trabajo ocasional o de asistencia en comida y techo, ya sea por parte de autoridades locales, órdenes religiosas o grupos de caridad. A estas familias se les sumaron todos los que volvían de otras regiones del país ya fueran para trabajar la tierra o conchabarse en los lavaderos de oro y la construcción del Túnel de las Raíces, a pocos kilómetros de Temuco. Este túnel forma parte del trazado férreo que llega hasta el límite con Argentina. Muchos de los trabajadores auríferos, en junio de 1934, hastiados de las durísimas labores, participaron en la revuelta de Ranquil, al noreste de la Araucanía.

13 A principios de 1932 se informaba que el Gobierno decidió enviar al sur la mayor cantidad posible de familias de parados y distribuirlas en los puntos donde se les pudieran suministrar los medios para trabajar, ABN, Diario Austral, Temuco, 1 de enero de 1932, pág. 10.

14 "Ha estado en nuestra ciudad un funcionario de la Dirección de Lavaderos contratando obreros para poner trabajo en algunos lavaderos, que habían estado sin explotar precisamente por falta de brazos", ABN, Diario Austral, Temuco, 12 de abril de 1934, pág. 1. En la ciudad de Traiguén, por ejemplo, durante varios meses se publicaron avisos en El Colono, de la siguiente tónica: "A los Sres. Agricultores o dueños de casa que deseen ocupar obreros o empleados domésticos pueden solicitarlos en la Inspección de Cesantía de esta ciudad", ABN, El Colono, Traiguén, 3 de enero de 1934, pág. 4.

15 "La mayor cuota de absorción de la cesantía le corresponde a los lavaderos de oro, donde actualmente debe haber ocupados alrededor de cincuenta mil obreros con sus familias", ABN, Diario Austral, Temuco, 12 de abril de 1934, pág. 1. La cifra nos parece bastante exagerada, ya que toda la Araucanía tenía menos de 400.000 habitantes en 1930: 50.000 lavadores de oro con sus familias implicaría un $50 \%$ de aumento demográfico en pocos meses. Según Bravo Acevedo, "El mercado de...", pág. 141, en 1932 "10.000 obreros mineros comenzaron a trabajar en las faenas de lavaderos de oro". 
La distancia entre las agencias estatales compradoras de oro y los lavaderos obligaba a los trabajadores a vender el polvo a precios más bajos a los pulperos del lugar. A cambio no recibían dinero en efectivo sino mercadería sobrevaluada. Una alta proporción de los desempleados que allí eran enviados a trabajar, terminaban volviendo a Temuco porque consideraban las condiciones de vida intolerablemente malas. ${ }^{16}$ En cuanto a la construcción del túnel, la situación no era mejor. La reducción de las faenas producía constantes despidos, por lo que se produjeron algunas huelgas en abril de 1934. Las bajas remuneraciones, las áridas condiciones laborales, la ausencia de dispensarios médicos y la larga serie de accidentes laborales tornaban aún menos tentadora la tarea en esa obra.

\section{Sindicatos rurales}

¿Cuál era la situación en los establecimientos rurales de la Araucanía? En la base, las condiciones laborales y legales de los trabajadores podían ser de muy variado tipo: había inquilinos, inquilinos-medieros, medieros, obligados, voluntarios, afuerinos, obreros especializados, etc. Las condiciones de las regalías y el salario en cada una de las unidades productivas dependían casi exclusivamente de la productividad del predio. ${ }^{17}$ Como ha señalado buena parte de la bibliografía disponible, este tipo de organización inhibía - al menos dificultaba muy notoriamente- la comunicación y la solidaridad dentro de los trabajadores, prevaleciendo las relaciones paternalistas con los propietarios. ${ }^{18}$

Debemos destacar que durante los años treinta se vivió en algunos valles de la Araucanía un avance de las presiones terratenientes sobre las pequeñas propiedades de colonos e indígenas, como parte del acelerado proceso de especulación con la tierra que desató la crisis del agro en ese período. Este proceso se expresó, por ejemplo, en los desalojos de colonos del valle de Ranquil a principios de 1934. A este constante "cercamiento" se le sumó la creciente conversión de las formas laborales tradicionales en

16 Entre los factores que generaban el abandono de las tareas auríferas o de construcción del túnel se contaban "la comida escasa, las habitaciones mal construidas y las inclemencias climáticas", Gallegos y Lara: La crisis de..., pág. 85. Chile, 1987.

17 Ortega, Emiliano: Transformaciones agrarias y campesinado, Cieplan Santiago de

18 Por ejemplo Valdés y otras, Masculino y femenino... 
relaciones salariales, incluyendo en este proceso a un buen número de comuneros mapuches, obligados a abandonar sus tierras y derechos comunitarios por la creciente y depredadora reducción de las propiedades familiares. Esta presión sobre los trabajadores se expresaba en la reducción de derechos de pastoreo, desdeñando la tradicional entrega de tierra al trabajador y prefiriendo el pago en dinero o en mercadería.

Quienes estaban en mejores condiciones de conformar agrupaciones estables eran los residentes permanentes de los fundos, esto es, los inquilinos y los medieros. El inquilinaje consistía en el arraigo obligado de los trabajadores y sus familias dentro de haciendas, recibiendo formas de remuneración mixta, en dinero y regalías (porción de tierra, huerto, talajes, casa y comida). ${ }^{19}$ Tenían habitaciones para ellos y sus familias (los inquilinos solían estar casados y ser padres) y una ración de tierra en potrero. El sistema de inquilinaje le ofrecía al trabajador un lugar donde habitar, una vivienda familiar y tierras para proveer a las necesidades más elementales. Brindaba un número de jornadas de trabajo relativamente alto, aunque con baja remuneración y algún grado de estabilidad según la voluntad del patrón y el paternalismo de cada hacienda. ${ }^{20}$

En la Araucanía el régimen de inquilinaje se diferenciaba del que regía en el centro del país ya que el inquilino no solía proporcionar más mano de obra que la suya y no tenía la obligación de aportar peones a la hacienda. Según Emiliano Ortega, era menor el peso del inquilinaje y la mediería, al igual que la cantidad de tierra cedida por los fundos. ${ }^{21}$ El trabajador recibía su remuneración con una proporción mayor de regalías, que no se solía dar en forma de potrero de tierra o en talaje como en el Chile central: se brindaba una casa con cerco y cierta cantidad de productos como trigo, papas y leña. Por otra parte, no existían en el sur trabajadores como los reemplazantes y los obligados.

Al igual que con los "pongos" de Perú, el sistema de hacienda le ofrecía a los trabajadores cierta cuota de seguridad frente al desempleo, la falta de tierras, la catástrofe climática, la enfermedad o el hambre, pero les

19 Ortega, Emilio: Transformaciones agrarias..., pág. 71.

20 Ibídem, págs. 73-4. Según Goicovic Donoso, Igor: "Surco de sangre, semilla de redención. La revuelta campesina de La Tranquilla (1923)", Valles. Revista de estudios regionales, núm. 3, Museo de La Ligua, La Ligua, Chile, 1997, pág. 86, el inquilino "recibía un pedazo de tierra y un jornal (regularmente en especies y regalías: tierra, talaje, galleta, ración de porotos y casa habitación), poseía una fuerte dependencia con su patrón (trabajaba en la hacienda 240 días al año) y contraía deudas en la pulpería, la que regularmente era propiedad de aquél".

21 Ortega: Transformaciones agrarias... 
exigía reciprocidad y una obediencia de tipo padre/hijo. ${ }^{22}$ Los derechos y bienes de los que gozaba el inquilino eran vivenciados y presentados como regalos y ejercicios de bondad paternal que el hacendado brindaba a sus hijos menores de edad antes que el resultado de una relación contractual. Es por eso que la vida cotidiana de la gran familia hacendal estuvo conformada por la convivencia de personas y relaciones sociales interiores y exteriores a la casa, pero no relacionadas armónica ni horizontalmente.

La bibliografía disponible ha insistido en que estos trabajadores estables representaban un caso de conciencia dependiente, estructurada a partir de esta verticalidad en las relaciones con el patrón y de la carencia de contacto social más allá de los límites del fundo. ${ }^{23}$ En la interpretación general, se lo considera una suerte de mano de obra cautiva, que asumía un acatamiento casi irrestricto al patrón, así como limitaciones en el marco de sus relaciones sociales. Afirmaba Arnold Bauer, que aunque "no cabe duda de que el inquilinaje cambió a lo largo del siglo antes de 1965 [...] sus relaciones económicas y sociales con los terratenientes permanecieron esencialmente intactas: todavía intercambiaban sus servicios laborales por precarios derechos a tierra y raciones; aun estaban más allá del alcance de la política y cultura urbanas". ${ }^{24}$

Tanto en la literatura como en los textos autobiográficos, los inquilinos aparecen como el estereotipo negativo de la masculinidad, en oposición al peonaje: docilidad, falta de iniciativa, dependencia del patrón. Las imágenes que se proyectaban del inquilino tenían que ver con la fidelidad, el paternalismo, la idea de un futuro compartido de trabajo constante como condición previa al progreso. En las haciendas coexistían familias consanguíneas, lo que contribuyó a construir socialmente la imagen de una gran familia en la que los inquilinos eran los hijos menores, y por lo tanto, los más vulnerables. Estos trabajadores permanentes aparecían en los discursos de los hacendados y de los analistas del agro como hombres deseables, a los cuales había que cuidar debido a su dedicación y responsabilidad en el trabajo.

22 Giordano, Verónica: "La resistencia simbólica en las haciendas de la sierra sur peruana", Estudios Sociales, núm. 11, Santa Fe, Argentina, 1996.

23 Parra Salinas, Alberto: "Tradición y cambio en la identidad campesina. Chada 1900-1995", Proposiciones, núm. 27, Sur, Santiago de Chile, 1996.

24 Bauer: La sociedad rural..., pág. 261. Goicovic Donoso: "Surco de sangre...", pág. 101 ha sido aun más radical: "Muchos de estos trabajadores agrícolas jamás tuvieron acceso a otro escenario cultural que no fuera el de la hacienda y el del trabajo de la tierra. Carentes de toda noción de lectoescritura y de toda expectativa de progreso social, circunscribían sus existencias al ámbito de reproducción cultural emanado de la propiedad latifundaria". 
Su interés principal radicaba en acceder a la tierra o asegurar su permanencia en ella, congelando los arrendamientos y dificultando los desalojos. Con intereses compatibles aparecían los embarcados en las tareas del oro y la construcción que alimentaban la posibilidad de usufructuar una parcela que les permitiera vivir con cierta seguridad y sin demasiados sobresaltos. En el contexto del fuerte desempleo de los años treinta y de avance terrateniente, la conjunción de objetivos entre inquilinos, mineros y otros trabajadores permitió la conformación de instituciones destinadas a obtener tierras para sus miembros (tal como el Sindicato de Aspirantes a Colonos e Inquilinos de Cautín fundado en 1939) y la supervivencia y desarrollo de una institución previa, como fue el Sindicato Agrícola de Lonquimay, fundado en 1929.25

Tanto el sindicato de Lonquimay como el de Cautín establecieron como interlocutores a agencias estatales como el Ministerio de Tierras o de Colonización. La presencia de los sindicatos de aspirantes a propietarios de la tierra es una prueba evidente de la persistencia de los problemas de acceso a terrenos para los hombres pequeños. Estos trabajadores gestionaban ante el gobierno central, siempre dentro del marco legal y utilizando los aparatos políticos existentes para vehiculizar las demandas: ya sea, como dijimos, a través de los sindicatos, pero también del Partido Socialista y el Demócrata. Antes que en las "acciones directas", el accionar sindical se centró en la difusión de la situación de los trabajadores rurales y el problema de la tierra, así como en una serie de gestiones tendentes a conseguir terrenos para dividir entre sus asociados y evitar los desalojos. Los sindicatos preferían las soluciones pacíficas y negociadas a las decisiones violentas e imprevistas, aunque en ocasiones defendieron la posición de los que eran lanzados o violentados en sus derechos. ${ }^{26}$

Es muy probable que sin la activa colaboración de cuadros militantes de partidos políticos de izquierda, llegados de Santiago, hubiese sido mucho más difícil sostener estas organizaciones sindicales. Como señaló Igor Goicovic, desde los años veinte la Federación Obrera Chilena enviaba

25 La búsqueda de tierras para desarrollar actividades productivas se hacía presente incluso en ámbitos urbanos. En 1931, los parados de Temuco pretendieron formar "una sociedad de colonización, con el fin de solicitar al Supremo Gobierno, se le concedan parcelas para sus asociados, acogiéndose a las leyes vigentes sobre esta materia", Diario Austral, Temuco, 10 de octubre de 1931, citado en Gallegos y Lara: La crisis de..., pág. 54.

26 Palacios Ríos: La violencia en..., pág. 62, ha hecho similares observaciones sobre el sindicato de Lonquimay: "condujo en la búsqueda de una solución que se acercaba más a la lucha reivindicativa que al enfrentamiento". 
delegados a diversos puntos rurales del país. ${ }^{27}$ Pero adjudicarle toda la responsabilidad de los actos al sector más "consciente" y politizado dentro de clase trabajadora no haría sino reforzar la interpretación de que los trabajadores rurales son sumisos .

En 1930, el Sindicato Agrícola de Lonquimay consiguió que se le asignaran algunas parcelas para distribuir entre sus afiliados. Este sindicato, con asociados en la región nororiental de la Araucanía, contó en su dirigencia con varios afiliados del Partido Comunista, destacando entre ellos Juan Segundo Leiva Tapia. ${ }^{28}$ De cualquier manera, otros sectores sociales y políticos estaban representados: había allí indígenas, inquilinos, colonos, pequeños propietarios, obreros del Túnel, lavadores de oro e incluso pulperos, que veían en la colonización la posibilidad de ampliar su cartera de clientes. El éxito logrado por el Sindicato en sus gestiones y la desesperante situación social que se desarrollaba a su alrededor se combinaron, dando por resultado un aumento notable de las afiliaciones a partir de 1930.

La heterogeneidad social de los participantes del Sindicato no impedía que se adoptaran objetivos comunes, como gestionar el acceso a tierras fiscales o exigir la entrega de terrenos correspondientes a aquellos que habían colonizado antes de 1891, como indicaba la Ley de Propiedad Austral sancionada en 1929. Mientras se respetaron las formas más institucionalizadas de reclamar a las autoridades, las relaciones al interior del sindicato se mantuvieron en un nivel menor de tensiones: de cualquier manera, existían divisiones entre los que seguían a Leiva Tapia y los que profesaban posturas más moderadas. ${ }^{29}$

27 Goicovic Donoso: "Surco de sangre...", pág. 102.

28 Martín Panemal, un reconocido dirigente mapuche integrante del partido ha recordado estos sucesos en sus memorias: "Los campesinos, al saber la amenaza que se les venía en su contra, se reunieron en una organización de colonos, para defender sus tierras ante el peligro de lanzamiento. Sus mejores dirigentes eran los compañeros Adán Sagredo, Simón Sagredo, Ana Sagredo, Ernesto Carter, José Lagos, el profesor Juan Leiva Tapia, todos militantes del Partido Comunista". Foerster, Rolf: Martín Painemal Huenchual. Vida de un dirigente mapuche, G.I.A., Santiago de Chile, 1982, pág. 51.

29 La biografía de Juan Segundo Leiva Tapia parece merecer un papel especial. Nacido en Chos Malal (Neuquén) en 1887, era de filiación comunista (incluso uno de sus hijos llevaba por nombre Juan Lenin). Sus padres ingresaron a Chile por Lonquimay en 1905. Era profesor de castellano y había completado el tercer año de abogacía en la Universidad de Córdoba. Participó activamente de reuniones de la Federación Obrera Chilena y de la Confederación Sindical Latinoamericana. Por sus actividades sindicales y políticas fue deportado de Argentina y Uruguay. Por esta misma razón se encontraba detenido en Victoria en 1929, cuando fue liberado por orden del presidente Ibáñez. Entonces fue nombrado subdelegado en Lonquimay, también por decisión del primer mandatario. 
El sindicato realizó varias diligencias, siendo incluso recibida una delegación por el presidente Ibáñez, pero no obtuvo más tierras después de 1930, por lo que las parcelas destinadas a los asociados fueron pequeñas. El envío de diversas comisiones técnicas del gobierno no permitió avanzar en la entrega de tierras ni la radicación de colonos. La desaparición del sindicato fue paralela a la desaparición física de la mayoría de sus dirigentes en julio de 1934, en la represión de la revuelta de Ranquil. ${ }^{30}$

Los inquilinos sufrían en forma permanente la violencia patronal - simbólica y física - y exhibían una posición muy endeble ya que dependían profundamente de la buena voluntad del hacendado para mantener su tierra y vivienda. Se veían obligados a aceptar las humillaciones permanentes, el derecho de pernada, ${ }^{31}$ la amenaza del desalojo y el maltrato de los mayordomos. ${ }^{32}$ El desalojo era lo más parecido a la catástrofe económica ya que dejaba a inquilinos y medieros sin tierras, inversiones ni vivienda.

Por eso las noticias sobre los desalojos merecían el máximo repudio de la prensa sindical..$^{33} \mathrm{~A}$ pesar de eso, en ningún momento los sindicatos procuraron conseguir sus propósitos por una vía extra-legal sino que se mantuvieron dentro de los carriles formalmente asignados. Un diputado que acompañó a delegados del Sindicato Agrícola de Lonquimay cuando visitaron Santiago, unos años antes de la revuelta de Ranquil, afirmó que

\footnotetext{
A los 5 meses debió renunciar a su puesto "ante el repudio generalizado de los habitantes de la región”, sostenía el Diario Austral, ABN, Temuco, 29 y 30 de junio de 1934. Fue candidato a diputado por el partido comunista en la región de Bío Bío. "Es un individuo hábil, de fácil palabra, y una cultura amplia" se informaba en La Tribuna del Sur, ABN, Temuco, 30 de junio de 1934, pág. 2. Para una caracterización novelada de Leiva Tapia, cfr. la pequeña novela de Manns, Patricio: Actas del Alto Bío Bío, Michay, Madrid, 1985. Una biografía que difiere en muchos puntos de la que aquí presentamos es la de Fahrenkrog, Harry: La verdad sobre la revuelta de Ránquil, Editorial Universitaria, Santiago de Chile, 1985.

30 Bohoslavsky, Ernesto: "Miedos y esperanzas. La revuelta de Ranquil (Chile, 1934)", en Masés, Enrique (comp.): Historia social 1990-2000, Publifadecs, General Roca, Argentina, 2000.

31 "La concepción de la familia hacendal aparece basada en el matrimonio para asegurar la reproducción de la descendencia y en las relaciones sexuales abiertas, concebidas como derecho del hacendado sobre las mujeres del inquilinaje" Valdés y otras, Masculino y femenino..., pág. 90.

32 Para un análisis de las relaciones entre los sexos y el clima de violencia al interior de los fundos, Valdés y otras: Masculino y femenino... Bauer, Arnold y Hagerman Johnson, Ann: “Tierra y trabajo en el campo chileno, 1850-1935", en Duncan, Kenneth y Rutledge, Ian (comp.): La tierra y la mano de obra en América Latina, FCE, México, 1987, consideran que el trato a los inquilinos no era tan severo como el que se pensaba a los peones afuerinos.

33 "11 familias de inquilinos fueron lanzadas al ambre y miseria en el fundo La Selva. Gran alarma pública a provocado el lanzamiento de 11 familias de inquilinos en el fundo La Selva, maximum cuando cada uno de estos ocupantes tenía de 14 a 32 años de permanencia en dichas tierras", ABN, Periódico La Palabra Campesina, Temuco, diciembre de 1939, pág. 5.
} 
ellos reconocían que no eran dueños de la tierra, pero también alegaban que habían labrado la tierra y levantado casas, por lo que se ofrecían a pagar la tierra con la intervención de la Caja de Colonización Agrícola. ${ }^{34}$

El Sindicato de Aspirantes a Colonos e Inquilinos de Cautín, nacido años más tarde, fue patrocinado por los partidos de centro-izquierda que componían el Frente Popular. A través de su prensa, el sindicato enfatizó los rasgos más humillantes de la situación de los trabajadores, remarcando el carácter de denuncia de su discurso:

\begin{abstract}
Vergüenza da recorrer las páginas de nuestra historia y ver que su enorme población campesina sigue como en los tiempos coloniales y en peores condiciones, pues, como en aquellos tiempos no había maquinismo se cuidaba la vida del trabajador, alimentándose en forma que pudiera resistir la jornada, pero ahora se mira a él como algo tan baladí. ${ }^{35}$
\end{abstract}

Así como se denunciaba socialmente la situación de los trabajadores rurales, se promovía públicamente la lucha contra el desalojo de inquilinos y por el cumplimiento de las obligaciones legales de los hacendados. El mensual La Palabra Campesina se mostró como una caja de resonancia de los conflictos de los ámbitos rurales de la Araucanía. Se esforzaba no sólo por difundir las noticias de índole gremial o social (desalojo, incumplimiento de leyes laborales, condiciones de vida, etc.) sino que además se internaba en el ámbito plenamente político-partidario. Evidenciaba una clara identificación entre su línea editorial y el Frente Popular, en el gobierno a fines de los años treinta. Esta vinculación forzaba a los mismos dirigentes sindicales a morigerar la fuerza de los reclamos a la administración nacional. Así, al conflicto central no se lo expresaba sólo como una lucha entre campesinos y terratenientes, sino que se le sobreimprimía una distinción de carácter político, en tanto se asignaban identidades partidarias a cada uno de estos dos sectores. El problema era, entonces, la expresión de la lucha entre ideas frentistas y derechistas. Es por eso que las campañas que inició este sindicato no estaban restringidas al acceso a la tierra sino que contenían consignas específicamente políticas, entre las que se contaba la lucha contra el clientelismo, el cohecho y la represión política.

34 Palacios Ríos: La violencia en..., cap. V y VI.

35 ABN, La Palabra Campesina, Temuco, diciembre de 1939, pág. 1. 
en uno de estos grandes fundos, uno de los muchos ricos, en una concentración campesina organizada por nuestro gran movimiento emancipador del trabajador de la tierra, practicó este viejo procedimiento del asado al palo y la empanada al horno, pero nuestra gente organizada desde hace 2 años no hizo caso y el trabajador campesino acudió en mayor número que otras veces al acto organizado aquel día [...] Campesino: el cohecho está penado por la ley no lo olvides. Vender el sufrajio significa labrarse su propia infelicidad. ${ }^{36}$

La virulencia de los ataques periodísticos a los propietarios agrícolas daba cuenta de la decisión de enfrentar abiertamente ciertas estructuras de dominación. De cualquier manera, la fortaleza de esta convicción no parece haber inclinado demasiado la balanza a favor de los trabajadores. Las posibilidades de enfrentar colectivamente en forma exitosa a la patronal eran bastante reducidas, dada la debilidad que ofrecía su posición y la serie de dispositivos políticos y sociales de control que desplegaban los propietarios. ${ }^{37}$

En lo que constituyó un verdadero hito en la historia del campesinado de la Araucanía, en agosto de 1939 se realizó una movilización de colonos y aspirantes a colonos, delegaciones de mapuches y pequeños agricultores, solicitando tierras. Esta "marcha de la Tierra" fue organizada por el propio sindicato y liderada por el Ministro de Colonización. Incluso la marcha se realizó "en homenaje a S. E. el Ministro". ${ }^{38}$ Concurrieron diversas delegaciones, entre las que destacaban la de la Colonia "Marmaduke Grove", la Confederación de Trabajadores de Chile, los maestros, el Partido Socialista, la Corporación Araucana, la Unión Araucana y el Sindicato de Aspirantes a Colonos de Cautín. Entre los manifestantes era posible encontrar letreros que exigían "división de los grandes fundos" y "Chile para los chilenos. Fuera los traidores". Comentaba la prensa que "no dejó de llamar la atención entre los desfilantes una larga columna de carre-

36 ABN, La Palabra Campesina, Temuco, 8 de mayo de 1940, pág. 2. Otra noticia del mismo periódico: "Se nos avisa que en Las Hortensias sigue la represalia contra los trabajadores de la tierra, por el enorme delito de tener ideas frentistas y sobretodo Socialistas y de una manera especial por ser aspirantes a colonos [...] ¿por qué temen estos señores feudales a la obra de esta poderosa organización que no ha tenido otro objetivo que luchar por radicar a los explotados inquilinos del Sur? [...] Es así como hay fundos donde atropellan a sus trabajadores con castigos corporales, lo que habla por sí solo de la insolencia que caracteriza a estos explotadores y chupasangres de la masa oprimida".

37 "La realidad es que los patrones de la Sociedad Nacional de Agricultura, no sólo fomentan el malestar en los campos, negando las mejoras a que tienen derecho los asalariados, sino que los están despidiendo por centenares, como ha ocurrido en Traiguén [...] o se les suprime por asesinato [...] por tratar de reivindicar para ellos y sus compañeros las mejoras de carácter económico y social a que ellos tienen derecho", ABN, La Voz del Sur, Temuco, 3 de febrero de 1940, pág. 9.

38 ABN, Diario Austral, Temuco, 13 de agosto de 1939, pág. 18. 
tas con familias de campesinos. Muchas de esas carretas ostentaban letreros como este: "queremos tierra". ${ }^{39}$

Entre las actividades desarrolladas por el sindicato se contaban los congresos de aspirantes a colonos, que recogían las opiniones de buena parte de los pequeños agricultores y trabajadores de la región. Los delegados a los congresos planteaban sus aspiraciones, centradas en torno a la tierra. $\mathrm{Y}$ alrededor de ese reclamo medular se articulaban otros pedidos: educación agrotécnica, ayuda financiera, etc. ${ }^{40}$ Es interesante señalar que los sindicatos se ofrecían como un ámbito que representaba a todos los trabajadores rurales por igual, tanto si eran pequeños propietarios, inquilinos o peones. ${ }^{41}$

\section{Trabajadores rurales: ¿organizaciones urbanas y conciencia nacional?}

En las áreas urbanas de la Araucanía era posible encontrar durante el primer tercio del siglo XX rastros de los conflictos sociales generados a partir de los reclamos de los trabajadores y de la militancia socialista. ${ }^{42}$ En

39 ABN, Diario Austral, Temuco, 14 de agosto de 1939, pág. 7. En términos apologéticos y de auto-referencia, los dirigentes del sindicato de aspirantes de Cautín mencionaban el origen de la organización: "La organización gremial había llegado al campo [...] pero en nuestra provincia nació a la vida pública hace un año en este gran movimiento organizado de masas campesinas. Primero organizó sus cuadros en los grandes fundos, luego después llegó a los pueblos, más tarde a la ciudad de Temuco, y por último el día 13 de agosto recién pasado presente ante la vista espantada de los latifundistas y timoratos de esta rejión su gran presentación oficial en esta ciudad. Un desfile de más de 15.000 trabajadores de la tierra marcharon", ABN, La Palabra Campesina, Temuco, diciembre 1939, pág. 1.

40 Entre los reclamos se encontraban: a) que los beneficiados por la colonización fueran residentes de esa provincia y de nacionalidad chilena. Se exigía finalizar con la serie de proyectos colonizadores que se basaban en la "importación" de trabajadores y agricultores europeos, rápidamente convertidos en grandes propietarios o trasladados a ámbitos urbanos; b) que se remensuraran todos los fundos denunciados como fiscales, con el claro objetivo de conocer el status real de las propiedades, tamaños y situación legal, al efecto de proceder a su parcelamiento y entrega en colonización; c) que los terrenos que resultaran ser fiscales se entregaran gratuitamente o a bajo precio a quienes lo solicitaran; d) que en las regiones con colonias se establecieran escuelas de experimentación agrícola, e) que se destinaran importantes fondos públicos a la adquisición y expropiación de fundos; f) ayuda financiera durante dos años al colono, quien estaba obligado a asociarse en cooperativas con el resto de los nuevos ocupantes del fundo; g) elección popular del administrador de la colonia. ABN, Diario Austral, Temuco, 14 de agosto de 1939, pág. 7.

41 ABN, La Palabra Campesina, Temuco, diciembre 1939, pág. 4.

42 Masés, Enrique y otros: Vida material, sociabilidad y cultura de los sectores populares en el sur de Chile y Argentina: 1885-1950, Universidad Nacional del Comahue, Neuquén, Argentina, 1998; y Quiroz Muñoz, Enriqueta: La plaza como expresión cultural de Temuco 1881-1920 (tesis), Universidad de Chile, Santiago de Chile, 1989. 
efecto, esta región tempranamente comenzó a mostrar señales de organización de los trabajadores urbanos, nucleados en gremios y sobre todo en mutuales y sociedades de socorros mutuos. Ciertas prácticas políticas y simbólicas de raigambre obrera y socialista como la celebración del $11^{\circ}$ de mayo encontraban su escenario físico en el reticulado temuquino. Este tipo de expresiones generaban en los sectores dirigentes un gran temor frente al ascenso del "peligro rojo" y llevaban a que se realizasen periódicas batidas policiales para reprimir cualquier manifestación de simpatía por la URSS. ${ }^{43}$ ¿Por qué es más difícil, pero no imposible, hallar el mismo nivel de agitación en el campo?

Las dificultades para avanzar en la sindicalización rural han sido bastante tratadas por la historiografía de Chile. Arnold Bauer ha rescatado el testimonio de un ministro del interior de los años treinta, señalando en qué consistía el accionar oficial frente a un conflicto desatado en el campo:

un grupo de carabineros llegaba a un fundo, acompañado de una caravana de camiones. Cuando los inquilinos estaban reunidos en el área, el oficial de carabineros ordenaba que los que querían continuar la huelga se pararan a su izquierda. El oficial ordenaba entonces que los huelguistas juntaran a sus familias, gatos, perros, gallinas y pertenencias y subieran a los camiones para ser expulsados. ${ }^{44}$

Este tipo de maniobras político-policiales fue el que permitió que el campo permaneciera, en buena parte, aislado de las principales corrientes políticas de Chile. Pero no todo puede reducirse a un mero ejercicio de represión de los conflictos. En una concepción original, José Bengoa ha sostenido que la aparente "tranquilidad" del campo chileno durante los siglos XIX y XX se debió, en realidad, a un amplio proceso de transferencia de los conflictos rurales a los ámbitos urbanos. ${ }^{45}$ De esta manera, a través de distintas vías liberadoras de tensión, el patrón de dominación terrateniente se aseguró y endureció. La constante huida de los peones, la voracidad latifundista y las opresivas condiciones de vida formarían parte

43 "Entre los que recibieron la visita de carabineros, estuvo el hojalatero José Arroyo, que había tenido la debilidad de expresar sus inclinaciones marxistas bautizando a su negocio con el nombre de 'El Soviet'. Se le comunicó que 'debía suprimir el letrerito' y le dieron aviso de que en Moscú lo necesitaban de modo 'que fuera preparando sus maletitas"”, Pino Zapata, Eduardo: Historia de Тетисо, Biografía de la capital de La Frontera, Escuelas Universitarias de la Frontera, Temuco, 1969, pág. 69.

44 Bauer: La sociedad rural..., pág. 270. 1990.

45 Bengoa, José: Historia social de la agricultura chilena, Sur, Santiago de Chile, tomo II, 
de un mismo sistema que derivó hacia la ciudad los problemas y tensiones generados en el agro. Aunque no coincidimos con la idea de que no pueden detectarse conflictos entre los trabajadores rurales, si reconocemos que, por lo general, los reclamos y debates más fuertes en torno a la situación del agro provenían de ámbitos urbanos.

La presencia de emblemas, figuras e ideologías de origen urbano es una constante al rastrear las prácticas organizativas y políticas de los trabajadores rurales, nacionales o mapuches. Varias organizaciones políticas y gremiales periódicamente enviaban delegados a los campos, para colaborar en la formación de gremios y células partidarias. Maestros, activistas y sindicalistas se convertían en vehículos cruciales de transmisión de ideologías, experiencias y marcos de referencia más generales. Los vericuetos de la política nacional y de partidos se fueron metiendo en las débiles organizaciones de los trabajadores rurales, condicionando las estrategias adoptadas y definiendo consignas y posiciones ideológicas. Pero a pesar de la intención manifiesta de introducir su militancia e ideología dentro del mundo rural, lo cierto es que la mayoría de las acciones se desplegaban en áreas urbanas y a través de los trabajadores allí radicados. Por lo tanto, el cariz de las actividades desarrolladas y las posiciones asumidas estaban lejos de las prácticas rurales habituales.

Las reuniones que se realizaban en algunos de los sindicatos combinaban una doble función: ser tanto ámbitos de sociabilidad informal y diversión como de formación y discusión. Según Andrés Bello, los sindicatos de Temuco realizaban gran variedad de actividades sociales con dos finalidades: obtener fondos para sostener la organización y ayudar a los asociados, así como "alegrar" las circunstancias en que se desarrollaban a causa de la Gran Crisis. ${ }^{46}$ En 1940, un periódico sindical informaba sobre una reunión celebrada en el Hogar Obrero:

Más de 100 obreros asistieron a esta reunión donde se desarrollaron números de variedades e hicieron uso de la palabra varios obreros tocando puntos de palpitante actualidad. Finalizó esta reunión con una once a los asistentes ${ }^{47}$.

No es extraño, entonces, encontrar que en 1941 fueron los propios gremios urbanos de la Araucanía los que solicitaron a los gobernantes un

46 Bello Maldonado, Andrés: Formas y lugares de diversión popular en Temuco 1930-1950. Un acercamiento histórico a través de testimonios orales (tesis), Universidad de la Frontera, Temuco, 1990, pág. 26.

47 ABN, El Luchador Obrero, Temuco, 13 de julio de 1940, pág. 3. 
"pronto despacho de la reglamentación de acuerdo con el Código de Trabajo, sobre sindicalización campesina", a la vez que expresaban el "deseo de que se impida el desalojo de ocupantes, obreros e inquilinos agrícolas" ${ }^{48}$ Es decir, el reclamo no provenía de los propios trabajadores rurales sino de otros gremios ya consolidados. De hecho, la presencia de organizaciones urbanas era clara, tanto en los aspectos gremiales como políticos. A lo largo de todo el período se puede observar la permanente intención de los partidos políticos de insertarse entre los trabajadores rurales y los mapuches, desplegando diversas estrategias de acercamiento a la "cuestión campesina" y asuntos anexos (colonización, créditos, títulos). ${ }^{49}$

Una parte de los trabajadores rurales (especialmente los afuerinos, sin domicilio ni actividad fija) a la hora de sus prácticas y opciones políticas adoptaban un marco preponderantemente nacional. Esta consideración se debía en buena parte a que la circulación física de los peones se convirtió en una fuerte formadora de experiencias sociales y un excelente vehículo de transmisión de ideas por todo el país. Según Pinto Vallejos el deambular peonal sirvió para que se socializara una forma de nacionalismo popular, opuesta a un nacionalismo estatal y con hegemonía burguesa. ${ }^{50}$ Aunque de alguna manera eran proyectos socio-culturales en tensión, también estaban en diálogo y permanentemente se ofrecían préstamos. Esas recorridas peonales permitieron que durante el siglo XIX fueran bastante homogéneas las prácticas culturales, festivas y religiosas en el "bajo pueblo" urbano y rural (fiestas, creencias, valores, formas de recreación). ${ }^{51}$

El deambular le agregó una dimensión nacional a la vida de los peones, rompiendo con las limitaciones mentales que ofrecía el sedentarismo de los trabajadores estables, como los inquilinos. Éstos vivían limitados por la patria chica y dentro de ella desarrollaban su universo cultural y sus prácticas cotidianas. Sólo con la conformación de los primeros sindicatos de inquilinos y de aspirantes a colonos comenzaron a romper con algunas

48 ABN, Diario Austral, Temuco, 2 de mayo de 1941, pág. 3.

49 Cfr. el aviso del Partido Agrario creando una oficina en Temuco para atender gratuitamente gestiones relacionadas con temas del agro, en ABN, A través de la Frontera, Temuco, 14 de enero de 1936 pág. 7. De la misma manera, las fuerzas de derecha se fijaron el objetivo de ampliar el apoyo dentro del campo. Cfr. la nota sobre la Juventud Falangista de Los Ángeles y su decisión de penetrar en el campesinado, Diario Austral, Temuco, 2 de mayo de 1940, pág. 7.

50 Pinto Vallejos, Julio: “¿Patria o clase? La guerra del Pacífico y la configuración de las identidades populares", ponencia en las XV Jornadas de Historia Económica, Tandil, Argentina, 1996.

51 Según Pinto Vallejos: “¿Patria o clase?...”, los festejos del 18 de septiembre, el respeto a la bandera tricolor y la recordación de los héroes patrios y el santoral católico formaban parte de la veneraciones populares, en algunos casos coincidentes con las fiestas "oficiales". 
de las estrecheces ideológicas que parecen haberlos caracterizado. Este proceso fue paralelo a la construcción y asunción de una identidad que quitaba del centro a la pertenencia a la hacienda y reforzaba identidades de mayor alcance (nacionales, partidarias o religiosas)..$^{52}$

\section{Saqueos, requisas, robos}

Sostuvimos que, en un contexto de fuerte paro y depresión económica, muchos de los desempleados o desalojados de fundos pensaban obtener una parcela para solucionar sus problemas económicos. Pero la esperanza de acceder a la tierra a través de los sindicatos iba por un camino de mediano o largo plazo que no siempre se auguraba exitoso. Y más de uno de estos trabajadores reflexionó como lo hizo John Maynard Keynes, en el sentido de que los cálculos para el largo plazo señalaban que todos estarían muertos. La existencia de las organizaciones sindicales antes descriptas no impedía que se desarrollaran otras "estrategias" para afrontar tareas más básicas como alimentarse a sí mismo y a su familia. Especialmente clara es la adopción de estas tácticas alternativas entre aquellos que pudieron llegar a Temuco. Fue por eso que hubo casos en que no se esperaba hasta el momento de llegada de la ayuda estatal o a ver los resultados de la gestión institucional: el problema del hambre se resolvió con expedientes más rápidos, algunos reñidos con la legalidad.

Para esos años, los asaltos desesperados se tornaron una constante espada de Damocles para los propietarios en la ciudad de Temuco. Mendicidad y hurto famélico eran realidades muy cercanas, aun para aquellos que eran beneficiados con alguna ayuda estatal o eclesiástica. ${ }^{53}$ En algunas ocasiones, bandas de desocupados salían de recorrida por los fundos cercanos a Temuco, efectuando "requisas" destinadas a darle mayor sustento a su dieta diaria.

Es que la alimentación cotidiana se encontraba en jaque por la creciente cantidad de desempleados que se iban albergando con sus familias o que iban entrando a los comedores populares. Es así que podemos encon-

52 Parra Salinas: "Tradición y cambio...”.

53 "Los desempleados que concurren al comedor de las Monjas de Convento de la Providencia tenían que manifestar solamente la necesidad de que se les proporcionara más cantidad de pan en el desayuno y especialmente alimentos en la noche, de lo que actualmente carecen por lo cual se ven obligados muchos de ellos a mendigar por los domicilios". ABN, Nuevos Tiempos, Temuco, 6 de julio de 1932, pág. 2. 
trar noticias acerca de "expropiaciones populares" en ricos fundos de alrededor de la capital:

\begin{abstract}
Algunos agricultores se presentaron ayer a las autoridades a denunciar que habían sido víctimas de algunos actos delictuosos al pedir limosna en sus fundos [... en ese momento, los desempleados que fueron a solicitar su ayuda ...] envalentonados por la buena atención que se les dispensaba, manifestaron que 2 ovejas era muy poco y que se les entregara una vaquilla y sin más trámite se apoderaron de ellas, y en presencia del propietario procedieron a darle muerte y a carnearla. Desde allí se dirigieron a otro fundo, en donde se apoderaron de un buey, al cual también dieron muerte, mientras intimidaban con su presencia al propietario. ${ }^{54}$
\end{abstract}

En otra ocasión, no fue necesario salirse del reticulado de Temuco para conseguir alimentos. En 1933 una partida de doscientos hombres asaltó y sustrajo de la bodega de José Cerda algunos cuantos sacos de legumbres destinadas al consumo inmediato. Los autores del robo resultaron ser desempleados que estaban alojados en uno de los albergues temporales organizados por la Municipalidad..$^{55}$

Hubo otros casos en que no se robaba alimentos sino otras mercaderías que eran fácilmente comercializables en la estación de ferrocarril o la plaza Pinto. Similar suerte corrían las lámparas del alumbrado público y el cuero de ganado malhabido. Precisamente, la estación del ferrocarril se convirtió en estos años en un área estigmatizada por la "decencia" temuquina. La concentración humana generada por el arribo de sujetos provenientes de ámbitos rurales de la Araucanía, principalmente trabajadores rurales y mapuches, el fuerte mercado negro y la difusión del tifus exantemático en esos años convirtieron a la estación en un "lugar maldito".

¿Qué había detrás de estas reacciones populares desesperadas, de escasa planificación y protagonizadas por grupos reducidos? Si bien es posible encontrar que algunos de estos actos contaron con el posterior apoyo de organizaciones de izquierda, como el caso del Partido Comunista en Ranquil, muchos eran el resultado del espontaneísmo famélico. Eran actos prácticamente espontáneos, o al menos con escaso nivel de organización. Resulta muy arduo ubicar a la mayoría de los comportamientos de los trabajadores rurales que hemos visto (saqueos, asaltos, robos) como parte de un movimiento obrero con conciencia de clase. Esto quizás resulta paradó-

54 Diario Austral Temuco, 27 de octubre de 1931, citado en Gallegos y Lara: La crisis..., pág. 56.

55 Gallegos y Lara: La crisis, pág. 78, y Pino Zapata: Historia de Temuco..., pág. 68. 
jico en un país como Chile, caracterizado por una vigorosa tradición sindical y una fuerte presencia de ideologías de izquierda entre los trabajadores. Ningún grupo estable puede adjudicarse la coordinación, representación o dirección de quienes ejercieron los asaltos, las requisas o incluso la revuelta de Ranquil. Este espontaneísmo se reforzaba por la opción que se tomó por las acciones directas en desmedro de las formas más tradicionales de gestión ante la autoridad política y usando los vehículos institucionales de uso más común (partidos, asociaciones, sindicatos, prensa, etc.). Estas acciones directas no necesariamente eran vividas por sus participantes como una actividad con connotaciones políticas. Además de no contar con la estructura de ningún grupo político o sindical organizado, por lo general se trataba de actos sin consignas reivindicatorias ni con propuestas más abarcadoras. Eran de escasa amplitud en lo que se refiere a la cantidad de sujetos involucrados y el beneficio obtenido. Como señaló E. P. Thompson, a la hora de describir las formas de resistencia de los trabajadores, se debe considerar un abanico mucho más amplio de acciones que las huelgas o sabotajes y descubrir el comportamiento de clase donde las autoridades sólo señalan un crimen. ${ }^{56}$

\section{Conclusiones}

La promesa de una California chilena se mostró definitivamente incumplible a partir de la década de 1930. La largamente ponderada " $p a z$ del trigo", conseguida con la derrota militar mapuche y la instauración del capitalismo agrario, daba señales de agotamiento en esa década. Miles de parados llegaron hasta esta región en búsqueda de trabajos de temporada en los lavaderos de oro o en la actividad agrícola: pero terminada la cosecha, se quedaban en la capital, Temuco, generando fuertes tensiones sociales. Allí los desempleados, muchos de origen rural, y sus familias llegaron a sumar hasta 9.000 personas, que debían ser mantenidas y sostenidas en una ciudad de 35.000 habitantes. Los problemas derivados de la alimentación, cuidado sanitario, educación y búsqueda de empleo para una masa tan importante de trabajadores puso en serios aprietos a la convivencia social en medio de una acentuada crisis económica.

56 Thompson, Edward: Tradición, revuelta y consciencia de clase, Crítica, Barcelona, 1984. 
A la presión generada por el regreso de estos trabajadores originarios de la Araucanía se le sumaba la presencia de aquellos muchos enviados por el gobierno, con la esperanza de "ubicarlos", al menos en tareas temporales. Estos sujetos eran en su mayoría trabajadores poco calificados, de deambular permanente y con una mayor y diversificada experiencia laboral e, incluso, sindical. Las carencias materiales generadas por el desempleo eran paliadas, en parte, por la posibilidad de acceder a una parcela que ofreciera cierta seguridad y disponibilidad de alimentos. Es por eso que en la Araucanía, muchos de los desocupados se agruparon en sindicatos de aspirantes a colonos, como forma de aunar esfuerzos en su lucha por la obtención de tierras. A ellos se le unieron los campesinos que deseaban evitar su desalojo. Estos sindicatos desdeñaron las formas de acción extralegales, especialmente las ocupaciones de fundos. Se limitaron a realizar peticiones, enviar cartas y realizar visitas protocolares a las autoridades nacionales para que se les brindara tierras y se detuvieran los desalojos. Estas redes institucionalizadas tenían por eje central el reclamo sobre la tierra: acceso, titulación, auxilio financiero, capacitación agrotécnica, etc. La serie de organizaciones creadas se abocaron a agotar las instancias legales existentes para retener o recuperar la tierra. Las más de las veces esta estrategia resultó absolutamente inútil y no hizo sino reafirmar la creencia de que el poder público estaba subsumido o supeditado al poder económico.

Estos sindicatos apostaron a la colaboración con las autoridades antes que a su enfrentamiento, pero el agravamiento de las condiciones de vida y la extensión temporal de la situación de paro, con la inestabilidad económica y psicológica que generan, empujaron a muchos parados a embarcarse en formas de comportamiento social reñidas con la legalidad y el orden público: asaltos a pulperías y galpones, requisas en los fundos, mendicidad y multiplicación de los hurtos fueron parte de las reacciones populares ante el desempleo. 